\title{
Preparation of Chitosan-Plasmid DNA Nanoparticles Encoding interleukin-12 and their Expression in CT-26 Colon Carcinoma Cells
} \author{
Faramarz Dobakhti ${ }^{\mathrm{d}}$, Farzaneh Lotfipour ${ }^{\mathrm{e}}$ \\ ${ }^{a}$ Faculty of Pharmacy, Tabriz University of Medical Sciences, Tabriz, Iran. \\ ${ }^{b}$ Biotechnology Research Center, Tabriz University of Medical Sciences, Tabriz, Iran. \\ ${ }^{\mathrm{c} I m m u n o l o g y}$ Research Center, Tabriz University of Medical Sciences, Tabriz, Iran. \\ ${ }^{\mathrm{d}}$ Faculty of Pharmacy, Zanjan University of Medical Sciences, Zanjan, Iran. \\ ${ }^{\mathrm{e}}$ Hematology and Oncology Research Center, Tabriz University of Medical Sciences, Tabriz, Iran.
}

Somayeh Hallaj-Nezhadi, ${ }^{\mathrm{a}, \mathrm{b}}$, Hadi Valizadeh ${ }^{\mathrm{a}}$, Siavoush Dastmalchi ${ }^{\mathrm{a}, \mathrm{b}}$, Behzad Baradaran ${ }^{\mathrm{c}}$, Mohammad Barzegar Jalali ${ }^{\mathrm{a}}$,

Received, April 5, 2011; Accepted, May 6, 2011; Published, May 6, 2011.

ABSTRACT - Purpose. Interleukin-12 (Il-12) as a cytokine has been proved to possess antitumor effects via stimulating the immune system. Non-viral gene delivery systems exhibit low toxicity and are easier to prepare compared to their viral counterparts. In this study, we aimed to prepare plasmid DNA loaded chitosan nanoparticles for expression of Il-12 and to evaluate their physicochemical characteristics, cytotoxicity and transfection efficiency in Murine CT-26 colon carcinoma cells. Methods. Nanoparticles were prepared using a complex coacervation process at different N/P ratios and characterized in terms of size, zeta potential, polydispersity index, morphology, encapsulation efficiency and polyplex formation. The cytotoxicities and transfection efficiencies of the prepared polyplexes were evaluated by MTT assay and ELISA (for hIL-12, p70), respectively. Results. Size and zeta potential varied from 76.73 to $867.03 \mathrm{~nm}$ and between 5.68 and $16.77 \mathrm{mV}$, respectively. Strong attachment of the DNA to chitosan was observed after polyplex preparation. Encapsulation efficiencies were high (72.97-94.87\%). The transfection efficiencies of the prepared complexes were obviously higher than those of naked pDNA when N/P ratios were between 16 and 60. Maximum level of phIL-12 expression was obtained at $(\mathrm{N} / \mathrm{P}=16)$ with mean particle size of $381.83 \pm 82.77 \mathrm{~nm}$ (polydispersity index $=0.44 \pm 0.066$ ) indicating the improved transfection of pUMVC3-hIL12 about 2.80 times compared to that of the naked pUMVC3-hIL12. Prepared polyplexes were nontoxic to CT-26 cells. Conclusions. Chitosan-DNA nanoparticles at $\mathrm{N} / \mathrm{P}=16$ with minimal cytotoxicity, can be used as suitable candidate for Il-12gene delivery.

This article is open to POST-PUBLICATION REVIEW. Registered readers (see "For Readers") may comment by clicking on ABSTRACT on the issue's contents page.

\section{INTRODUCTION}

It has been at least a century that the immune system has been utilized for tumor treatment, namely a treatment modality referred to as cancer immunotherapy (1). It has been proved that the host immune system has a main role in recognition as well as destruction of cancer cells (2). Cytokine genes delivery to cancerous cell as cancer gene immunotherapy alters the local tumor environment in order to induce an anti-tumor immune response to facilitate its eradication $(3,4)$.

Gene transfer of cytokines or other immunotherapeutic agents for host immune response enhancement, in comparison with therapeutic protein therapy, avoids the need for production and purification of large amounts of recombinant proteins. Furthermore, genetic immunotherapy has the ability to deliver immune mediators in a more efficient and safe manner; as transfer of genes encoding therapeutic proteins can give rise to more "natural" sustained protein levels in vivo, and also decrease problems with immunotherapeutic agents being toxic at high doses while demonstrate short circulating half-lives (1).

IL-12 is a heterodimeric cytokine composed of two subunits of $\alpha$-chain ( $35 \mathrm{kD}$ as $\mathrm{p} 35$ ) and $\beta$-chain (40 $\mathrm{kD}$ as $\mathrm{p} 40$ ) covalently linked by a disulfide bridge (5). Primarily produced by activated macrophages, monocytes, and dendritic cells (DCs),

Corresponding Author: Farzaneh Lotfipour; Faculty of Pharmacy, Tabriz University of Medical Sciences, Tabriz Iran; Email: lotfipoor@tbzmed.ac.ir 
IL-12 has a pivotal role in proinflammatory and immunoregulatory functions (6). Investigations demonstrated that IL-12 possesses superior antitumor activity in comparison with the different cytokines. IL-12 has been shown to be efficacious in prevention of primary tumor growth (7-9).

IL-12 possesses potent anti-angiogenic activity produced by neutrophils, macrophages and dendritic cells (10-12). Since antitumor effect of IL12 is related to the promotion of antitumor immunity and the inhibition of angiogenesis, this cytokine have no direct effect on tumor cells in vitro (13).

In general, the application of recombinant Il-12 in humans has been very restricted. Preclinical toxicity evaluations in several animal species have documented adverse IL-12-induced hematopoietic, intestinal, hepatic, and pulmonary effects (14). On the other hand, delivery of IL-12 protein necessitates frequent injections due to its instability and short half-life subsequent to bolus administration (15, 16). Thus, the local administration of gene encoding IL-12 may be less toxic than systemic delivery of this cytokine as recombinant protein.

The general vectors used in gene delivery systems consist of viral and non-viral delivery systems. Although viral gene delivery systems possess high efficiency in various human tissues, there are concerns in relation to immunogenicity, toxicity and possible viral gene integration into the human genome. On the other hand, non-viral vectors have low toxicity and are easy to prepare. In addition, non-viral delivery systems induce no specific immune response and can carry higher amounts of genetic materials without limitation on the size of the gene to be delivered $(17,18)$.

In fact, nanosized particles are able to interact with and cross mucosal surfaces (19), cross bloodbrain barrier, enhance cellular uptake, escape endolysosomal compartments and release genes continuously within the cell (20). Indeed, there is less interaction between the cationic polymers and serum components. Furthermore, it has been demonstrated that naked plasmid DNA is quickly taken up by sinusoidal cells such as Kupffer and liver sinusoidal endothelial cells. Since it seems to be as a result of the high anionic charge of plasmid DNA (21); thus, use of cationic polymers will lead to decrease in clearance of polyplex and control of tissue distribution due to elimination of negative charge of DNA. Of the cationic polymers investigated so far, chitosan has been introduced as a potential gene carrier (22-25). Chitosan is a linear biodegradable, biocompatible and non-allergenic polysaccharide. This polymer, with high ability of binding to nucleic acids, is composed of randomly distributed N-acetyl-D-glucosamine and $\beta$-(1,4)linked D-glucosamine (26). Chitosan as a weak base with an apparent pKa of 6.5 possesses a high density of amino groups and is soluble in $\mathrm{pH}$ values below 6 where most of the amino groups are protonated $(22,27)$. Chitosan generates a positively charged complex in interaction with DNA leading to its cellular interaction and uptake (28). More interestingly, chitosan as a mucoadhesive polymer, is able to enhance drug absorption by re-arranging the tight junction proteins (24). Chitosan can swirl across the membrane bilayer and facilitate the cellular uptake of the polyplex (26). Moreover, chitosan nanoparticles were found to have the ability of entering the nuclear membrane and delivering the therapeutic agent directly into the nucleus (24). Chitosan-DNA complexes have been shown to protect DNA from digestion by DNase I in vitro $(24,27)$.

To date, several investigations have been done in order to deliver Il-12 gene via viral vectors (29-31) as well as some non-viral carriers including gene gun (19), liposomes $(32,33)$ and electroporation (34). However, there are very restricted reports (15, 35-38) indicating the application of polyplexes to this end. Thus, considering the advantages of chitosan, we aimed to prepare the plasmid DNA loaded chitosan nanoparticles for expression of Il12 , and to evaluate the physicochemical characteristics, cytotoxicity and transfection efficiency of the prepared complexes in Murine CT26 colon carcinoma cells.

\section{MATERIALS AND METHODS:}

\section{Materials}

Chitosan(MW 190000-310000 kDa, 75-85\% degree of deacetylation), 3-(4,5-dimethylthiazol-2-yl)-2,5 diphenyl tetrazolium bromide (MTT), potassium dihydrogen phosphate, disodium hydrogen phosphate, kanamycin, glycin, trypan blue solution were purchased from Sigma-Aldrich (Munich, Germany), sodium hydroxide, ethylene diamine tetraacetic acid (EDTA), tris base, ethidium bromide, dimethyl sulfoxide, Luria-Bertani broth, 
sodium chloride, calcium chloride, glycerol, agar, isopropyl alcohol, sodium bicarbonate, acetic acid, sodium acetate, sodium sulphate were purchased from Merck (Darmstadt, Germany), Lipofectamine $^{\mathrm{TM}} 2000$ Transfection Reagent was obtained from Invitrogen (Carlsbad, CA, USA), endotoxin-free plasmid megaprep Kit was obtained from Qiagen (Santa Clarita, CA, USA), agarose, Escherichia coli K12 were obtained from Cinnagen (Tehran, Iran), fetal bovine serum, trypsin-EDTA, penicillin-streptomycin, RPMI-1640 were purchased from Gibco (Invitrogen Inc., Burlington, Ontario, Canada), murine CT-26 colon carcinoma cells was obtained from National Cell Bank of Iran (Pasteur Institute, Iran), pUMVC3-hIL12 was purchased from Aldevron (Fargo, ND, USA), DNA ladder $1 \mathrm{~kb}$, Xho I and Sal I were obtained from Fermentas (St. Leon-Rot, Germany), 96 well cell culture plate, 24 well cell culture plate, cell culture flask were purchased from SPL (Life Sciences Inc., Gyeonggi-do, Korea), cryotube was purchased from Nunc (Denmark), tryptone, yeast extract were purchased from Quelab (Montreal, Quebec, Canada), syringe-driven filter, vacuum-driven filter were obtained from JetBiofil (Guangzhou, China), and human IL-12p70 ELISA kit was obtained from Utrecht (The Netherlands).

\section{Equipments}

Zetasizer 3000 (Malvern Instruments, Southborough, MA, USA), $\mathrm{CO}_{2}$ Incubator (Memmert, Schwabach, Germany), incubator shaker (Akhtaryan, Tehran, Iran), microplate reader (Biotek, Winooski, USA), transmission electron microscope (LEO 906, Germany), UV spectrophotometer (Shimadzu, Japan), centrifuge (Beckman, Brea, USA), and inverted microscopes (EUROMEX, Suarlée, Belgium) were used.

\section{Plasmid isolation}

PUMVC3-hIL12 plasmid DNA encoding human IL-12 was used. The plasmid DNA is $6115 \mathrm{bp}$ in size and contains CMV IE promoter. The plasmid DNA was amplified in Escherichia coli K12, extracted and purified by the alkaline lysis method using mega DNA preparation kit (Qiagen). The quality of the purified plasmid DNA was evaluated by electrophoresis in agarose gels after enzymatic digestion by Xho I and Sal I. The quantity of the purified plasmid DNA was assessed spectrophotometrically at $260 \mathrm{~nm}$.

\section{Preparation of chitosan-DNA nanoparticles}

Chitosan-DNA nanoparticles were prepared using a complex coacervation process nearly according to earlier reports of Chew et al. and Gao et al. $(39,40)$. Briefly, Chitosan was dissolved in $1 \%$ acetic acid with gentle heating and $\mathrm{pH}$ of the solution was adjusted to 5.5-5.7. The solution was diluted to concentrations ranging from 0.01 to $1.0 \%$ of chitosan (w/v). The chitosan solution was readjusted to $\mathrm{pH} 5.5$ and sterile-filtered through a $0.45 \mu \mathrm{m}$ filter. Equal volumes of different chitosan solutions and DNA solutions of $100-200 \mu \mathrm{g} / \mathrm{ml}$ in $25 \mathrm{mM}$ of sodium sulfate solution at $55^{\circ} \mathrm{C}$ were rapidly mixed and vortexed at maximum speed for 45 seconds. The resulting polyplexes were allowed to sit at room temperature for $30 \mathrm{~min}$ for stabilization.

Measurement of particle sizes, polydispersity index and zeta-potential of the pUMVC3-hIL12 loaded chitosan nanoparticles

Evaluation of particle size, polydispersity index, and zeta potential of the pUMVC3-hIL12 loaded chitosan nanoparticles were performed by zetasizer nano particle analyzer (Nano ZS, Red badge, ZEN3600).

\section{Transmission electron microscopy}

Particle morphology of the selected pUMVC3hIL12loaded chitosan nanoparticles was determined by transmission electron microscopy (TEM). One drop of the selected DNA/chitosan nanoparticles was placed on a copper grid and stained with $1 \%$ uranyl acetate solution for $5 \mathrm{~s}$. The grid was allowed to dry further for $10 \mathrm{~min}$ and was then examined with the electron microscope.

\section{Polyplex formation of the pUMVC3-hIL12 loaded chitosan nanoparticles}

A widely used technique to study the DNA condensation is gel electrophoresis (41). Free plasmid DNA and prepared chitosan-DNA nanoparticles were applied into a $0.9 \%$ agarose gel containing Tris-acetate/EDTA buffer (TAE, $\mathrm{pH}$ 8) at constant voltage $(100 \mathrm{~V})$. Then, the gel was stained with ethidium bromide and was visualized under UV-light and the association of pDNA was checked using the gel documentation system. 


\section{Evaluation of encapsulation efficiency}

The amount of plasmid DNA encapsulated in the chitosan nanoparticles was calculated by considering the difference between the total amount of DNA added in the preparation medium through the coacervation process and the amount of nonentrapped DNA remaining in the supernatant after centrifugation (40000 g, $15 \mathrm{~min}$ ) of prepared nanoparticles. For this purpose, the supernatant was spectrophotometrically analyzed at $260 \mathrm{~nm}$ for DNA concentration (42).

\section{Cell line and cell culture}

Murine CT-26 colon carcinoma cells were incubated in RPMI-1640 (Gibco, Invitrogen Inc., Burlington, Ontario, Canada) supplemented with $10 \%$ FBS, streptomycine at $100 \mathrm{mg} / \mathrm{ml}$, and penicillin at $100 \mathrm{U} / \mathrm{ml}$. The cells were maintained at $37^{\circ} \mathrm{C}$ in a humidified $5 \%$ CO2-containing atmosphere.

\section{Evaluation of Cytotoxicity}

Cytotoxicity of the pUMVC3-hIL12 loaded chitosan nanoparticles was evaluated by the MTTbased cytotoxicity assay in murine CT-26 colon carcinoma cells. MTT assay is based on the ability of living cells to reduce a water-soluble yellow dye (MTT) to a purple colored formazan precipitates product by mitochondrial reductase enzymes. The cells were seeded in a 96-well plate at a density of $5 \times 10^{4}$ cells $/ \mathrm{cm}^{2}$ in $100 \mu \mathrm{l}$ of RPMI-1640 medium supplemented with $10 \%$ fetal bovine serum (FBS) and incubated for 24 hours at $37^{\circ} \mathrm{C}$ under $5 \% \mathrm{CO}_{2}$. Afterward, the medium was removed and supplied with $200 \mu 1$ of fresh culture medium. Subsequently, pDNA loaded chitosan nanoparticles were added to the cells at a dose of $2.5 \mu \mathrm{g}$ pUMVC3-hIL12/well. Non-treated cells and cells treated with naked plasmid DNA and lipofectamine ${ }^{\mathrm{TM}}$ were used as controls and incubated for the same duration of time. Following 48 hours of incubation at $37{ }^{\circ} \mathrm{C}$ under $5 \% \mathrm{CO} 2$, the medium was removed and fresh cell culture medium was added, then the cells were incubated with $20 \mu \mathrm{l}$ MTT $(0.5 \mathrm{mg} / \mathrm{ml}$ MTT in medium) for 4 hours. Subsequently the medium was removed, and the formazan precipitates formed in living cells were dissolved in $200 \mu \mathrm{LMSO}$ and $25 \mu 1$ glycine buffer per well. Relative viability (\%) was calculated based on absorbance at $570 \mathrm{~nm}$ using an ELISA plate reader. Viability of nontreated control cells was arbitrarily defined as
$100 \%$. The relative cell viability was calculated as $[\mathrm{Abs}]_{\text {sample }} /[\mathrm{Abs}]_{\text {control }} \times 100$. Data are presented as mean $\pm \mathrm{SD}(\mathrm{n}=4)$.

\section{In vitro transfection studies}

Murine CT-26 colon carcinoma cells were seeded into 24-well plates at a density of 80000 cells/well in $1 \mathrm{ml}$ of RPMI-1640 medium supplemented with $10 \%$ FBS and incubated for 24 hours at $37^{\circ} \mathrm{C}$ under $5 \% \mathrm{CO} 2$. Prior to transfection, the medium was removed and the cells were rinsed with PBS $(\mathrm{pH}$ 7.4), then supplied with $900 \mu \mathrm{l}$ of RPMI-1640 medium without FBS. The cells were incubated with chitosan/DNA nanoparticles at concentration of $5 \mu \mathrm{g}$ pUMVC3-hIL12/well for 6 hours at $37^{\circ} \mathrm{C}$ under 5\% CO2 atmosphere. Serum-free medium was replaced with RPMI-1640 medium supplemented with $10 \% \mathrm{FBS}$ and incubated for another 48 hours at $37^{\circ} \mathrm{C}$ under $5 \% \mathrm{CO} 2$. Nontreated cells and cells transfected with naked plasmid (as negative controls) as well as Lipofectamine TM 2000/DNA complexes (as positive controls) were used and incubated for the same duration of time. Lipofectamine ${ }^{\mathrm{TM}} 2000$ is a cationic liposome based reagent that provides high transfection efficiency in vitro but its high toxicity and instability in the presence of serum confines its in vivo applications (43, 44). Lipofectamine $^{\mathrm{TM}} /$ pDNA complexes were prepared with a 1:2.5 ratio of pDNA:Lipofectamine TM according to manufacturer's protocol in RPMI 1640 medium devoid of FBS. All experiments were done in triplicates, with two separate experiments to demonstrate reproducibility.

\section{Determination of transfection efficiencies}

For quantitative analysis of the pUMVC3-hIL12 expression, the human IL-12p70 enzyme-linked immunosorbent assay (ELISA) Kit was used according to the manufacturer's instructions. For this purpose, the collected culture supernatants were analyzed for the measurement of hIL-12 p70. The amount of the protein was determined as picogram per ml.

\section{STATISTICAL ANALYSIS}

Statistical testing was carried out using GraphPad Prism software. The student t-test was performed to assess the difference between treatment and control 
groups and $\mathrm{P}<0.05$ considered as a statistically significant difference.

\section{RESULTS}

The pUMVC3-hIL12 loaded chitosan nanoparticles formation and measurement of particle size, polydispersity index, and zetapotential

Chitosan coacervation formed in consequence of $\mathrm{Na}_{2} \mathrm{SO}_{4}$ induced desolvation of the local water environment. The size of chitosan-DNA nanoparticles is given in Table. 1 and depicted in Figure 1 and 2 as well. Particle size increased with the increasing N/P ratio (Nitrogen of chitosan/Phosphate of pDNA) confirming that the particle size of chitosan -DNA complexes were dependent on the N/P ratio. At N/P of 2, the particle size of the complexes was not monodispersed. However, practically uniform particles were obtained using 100-200 $\mu \mathrm{g} / \mathrm{ml}$ DNA and $0.02 \%$ $0.1 \%(\mathrm{w} / \mathrm{v})$ chitosan with particle size ranging from 76.73 to $867.03 \mathrm{~nm}$. Particle size distribution profile of F6 containing $0.08 \%$ of chitosan is shown in Figure 3 for instance. Furthermore, polydispersity index increased with the increasing of N/P ratio (Table 1).

The particles were nano-sized when $100 \mu \mathrm{g} / \mathrm{ml}$ DNA and below $0.3 \%$ of chitosan were used. Also in the case of the particles prepared using $200 \mu \mathrm{g} / \mathrm{ml}$ DNA and below $0.5 \%$ of chitosan, the particles were found to be nano-sized. These results indicate that at N/P ratios above 4 , the complexes were nano-sized.. The increase in particle size of chitosan-DNA complexes with increasing N/P ratio was also reported by Ishil and coworkers (45) and Ozgel and Akbuga (46).

Zeta potential of pUMVC3-hIL12 loaded chitosan nanoparticles is given in Table 1. At N/P ratio of 2 , the zeta potential was approximately neutral. The zeta potential was positive and increased by increasing the chitosan concentration in the constant DNA concentration. Zeta potential of F1-F10 found to be higher than those of F11F20, due to the lower amount of DNA used .This fact can also be clearly noted in Figure 4 and Figure 5.

\section{Transmission electron microscopy}

A typical transmission electron microscopy (TEM) image of pUMVC3-hIL12 loaded chitosan nanoparticles using $100 \mu \mathrm{g} / \mathrm{ml}$ DNA and $0.08 \%$ chitosan (F6) is shown in Figure 6. As it can be seen from this figure, the particles were about 400 $\mathrm{nm}$ in size and spherical in shape.

\section{Polyplex formation of the pUMVC3-hIL12 loaded chitosan nanoparticles}

The ability of the chitosan nanoparticles to entrap pDNA was studied using the agarose gel electrophoresis technique and the obtained results were compared to that of untreated control DNA. The results are shown in Figure 7: the intact DNA is seen in lane 2, while complexes of chitosan-DNA were loaded in lanes 3-22, respectively. As it can be seen from this figure, most of the DNA in lanes 322 remains in the wells and no additional or clear unbound DNA band was seen which demonstrates a strong attachment of the DNA to chitosan.

\section{Study of encapsulation efficiency}

The amount of DNA loaded in the nanoparticles was calculated as encapsulation efficiency (\%). As it can be seen from table 1 and Figures 8 and 9, encapsulation efficiencies showed a decreasing trend with increasing of the chitosan concentration. For instance, encapsulation efficiency of the formulation containing $0.02 \%$ (F1) chitosan was $85.42 \%$ whereas that of the formulation containing $1 \%$ (F11) chitosan was $68.83 \%$. Also for the formulations of F11 and F20, encapsulation efficiencies are found to be 87.33 and 72.97 respectively.

\section{Evaluation of Cytotoxicity}

The cell toxicity of chitosan-DNA nanoparticles was investigated by MTT-based cytotoxicity assay in murine CT-26 colon carcinoma cells. As shown in Figure 10, all prepared polyplexes showed no acute cell toxicity in murine CT-26 colon carcinoma cells at concentrations higher than those used for transfection studies. The average cell viabilities were almost over $90 \%$. The least cell viability was found to be $80.2 \%$ for F3. In contrast, Lipofectamine/phIL-12 complex-based transfection resulted in less than $70 \%$ cell viability. These results suggest that chitosan is biocompatible and low toxic gene transfer vector. It is feasible to use repeated administrations or increase the dose of the DNA/chitosan complex owing to low cytotoxicity of chitosan. 


\section{In vitro transfection studies}

Figure 11 compares the transfection efficiencies of the different DNA/chitosan formulations in CT-26 carcinoma cells. At N/P ratios of $4-12$, the transfection efficiencies of chitosan polyplexes were not remarkably different from that of the naked DNA. At N/P ratios between 16 and 60, the transfection abilities for all DNA/chitosan formulations were obviously higher than for the naked DNA. DNA/chitosan formulations showed maximum transfection efficiency at N/P ratio of 16 . Thus, DNA/chitosan nanoparticles could improve transfection of pUMVC3-hIL12 about 2.80 orders of magnitude compared to the naked plasmid DNA. However, its transfection ability was less effective than that of the lipofectamine ${ }^{\mathrm{TM}}$ formulation in the studied gene-cell combination (Figure 12). Transfection with all formulations prepared using $200 \mu \mathrm{g} / \mathrm{ml}$ pDNA (F11-F20) produced low gene expression compared to naked plasmid DNA (data not shown).

\section{DISCUSSION}

Noteworthy progress towards the development of nonviral gene carriers has been made to date in overcoming the current problems related to viral vectors in safety, immunogenicity and mutagenesis $(47,48)$. Chitosan/DNA complexes have been taken into consideration as candidate for gene delivery. Immunotherapy-based strategies for treating cancer, such as IL-12, try to increase the local and systemic immune response against the cancer cells and possibly provide a less toxic approach for cancer treatment. IL-12 has been shown to have superior antitumor activity compared to other cytokines. To get optimal results, cytokines are required to be available over an extended period of time, which is not possible with recombinant IL-12 protein owing to its short half-life (16). Hence, gene therapy using Chitosan/DNA nanoparticles possibly provide noteworthy advantages over recombinant protein therapy due to the ability to produce sustained levels of IL-12 in the tumor location with therapeutic effect devoid of dose-limiting systemic toxicities.

Table 1. Formulations, particle sizes, polydispersities, zeta potentials, and encapsulation efficiencies of pUMVC3hIL12 loaded chitosan nanoparticles

\begin{tabular}{|c|c|c|c|c|c|c|}
\hline Formulation & $\begin{array}{l}\text { pDNA } \\
(\mu \mathrm{g} / \mathrm{ml})\end{array}$ & $\begin{array}{l}\text { Chitosan } \\
\text { Concentration } \\
(\mathrm{W} / \mathrm{V} \%)\end{array}$ & $\begin{array}{l}\text { Average } \\
\text { Polydispersity }\end{array}$ & $\begin{array}{l}\text { Average Particle } \\
\text { Size }(\mathrm{nm}) \pm \\
\text { STD }\end{array}$ & $\begin{array}{l}\text { Average Zeta } \\
\text { Potential }(\mathrm{mV}) \\
\pm \text { STD }\end{array}$ & $\begin{array}{l}\text { Average } \\
\text { Encapsulation } \\
\text { Efficiency }(\%) \\
\pm \text { STD }\end{array}$ \\
\hline F1 & 100 & 0.02 & $0.24 \pm 0.006$ & $89.07 \pm 9.05$ & $5.90 \pm 0.92$ & $85.42 \pm 13.48$ \\
\hline $\mathrm{F} 2$ & 100 & 0.03 & $0.35 \pm 0.014$ & $76.73 \pm 43.55$ & $6.26 \pm 0.84$ & $88.83 \pm 3.31$ \\
\hline F3 & 100 & 0.04 & $0.32 \pm 0.038$ & $84.16 \pm 13.16$ & $7.16 \pm 1.32$ & $84.33 \pm 9.02$ \\
\hline F4 & 100 & 0.05 & $0.96 \pm 0.068$ & $144.17 \pm 25.65$ & $11.33 \pm 1.93$ & $82.30 \pm 3.82$ \\
\hline F5 & 100 & 0.06 & $0.33 \pm 0.034$ & $295.60 \pm 30.70$ & $12.30 \pm 2.07$ & $82.37 \pm 2.51$ \\
\hline F6 & 100 & 0.08 & $0.44 \pm 0.066$ & $381.83 \pm 82.77$ & $14.77 \pm 2.35$ & $82.17 \pm 5.61$ \\
\hline F7 & 100 & 0.1 & $0.27 \pm 0.034$ & $867.03 \pm 61.48$ & $14.37 \pm 1.86$ & $75.73 \pm 6.38$ \\
\hline F8 & 100 & 0.3 & $0.27 \pm 0.009$ & $1181.57 \pm 259.28$ & $18.23 \pm 3.39$ & $73.17 \pm 4.10$ \\
\hline F9 & 100 & 0.5 & $0.36 \pm 0.011$ & $1244.33 \pm 192.54$ & $18.67 \pm 4.06$ & $77.27 \pm 4.31$ \\
\hline F10 & 100 & 1 & $0.23 \pm 0.027$ & $1466.67 \pm 210.97$ & $30.50 \pm 5.11$ & $68.83 \pm 5.39$ \\
\hline F11 & 200 & 0.02 & $0.22 \pm 0.136$ & $94.78 \pm 9.55$ & $7.74 \pm 0.71$ & $87.33 \pm 6.43$ \\
\hline F12 & 200 & 0.03 & $0.37 \pm 0.014$ & $88.23 \pm 1.63$ & $10.93 \pm 0.59$ & $87.80 \pm 8.16$ \\
\hline F13 & 200 & 0.04 & $0.39 \pm 0.001$ & $105.26 \pm 19.23$ & $11.57 \pm 0.50$ & $89.90 \pm 1.44$ \\
\hline F14 & 200 & 0.05 & $0.41 \pm 0.011$ & $103.65 \pm 12.15$ & $11.70 \pm 1.23$ & $91.53 \pm 3.44$ \\
\hline F15 & 200 & 0.06 & $0.44 \pm 0.006$ & $94.78 \pm 17.71$ & $12.17 \pm 1.63$ & $89.50 \pm 2.44$ \\
\hline F16 & 200 & 0.08 & $0.60 \pm 0.091$ & $110.05 \pm 14.64$ & $11.27 \pm 1.07$ & $81.33 \pm 3.37$ \\
\hline F17 & 200 & 0.1 & $1.00 \pm 0.000$ & $145.93 \pm 35.15$ & $13.37 \pm 0.98$ & $79.38 \pm 3.10$ \\
\hline F18 & 200 & 0.3 & $1.00 \pm 0.000$ & $267.43 \pm 14.84$ & $13.60 \pm 1.59$ & $79.07 \pm 4.18$ \\
\hline F19 & 200 & 0.5 & $0.25 \pm 0.003$ & $198.77 \pm 87.39$ & $16.77 \pm 2.72$ & $76.90 \pm 6.15$ \\
\hline F20 & 200 & 1 & $0.27 \pm 0.028$ & $1065.00 \pm 69.16$ & $24.37 \pm 1.05$ & $72.97 \pm 6.15$ \\
\hline
\end{tabular}




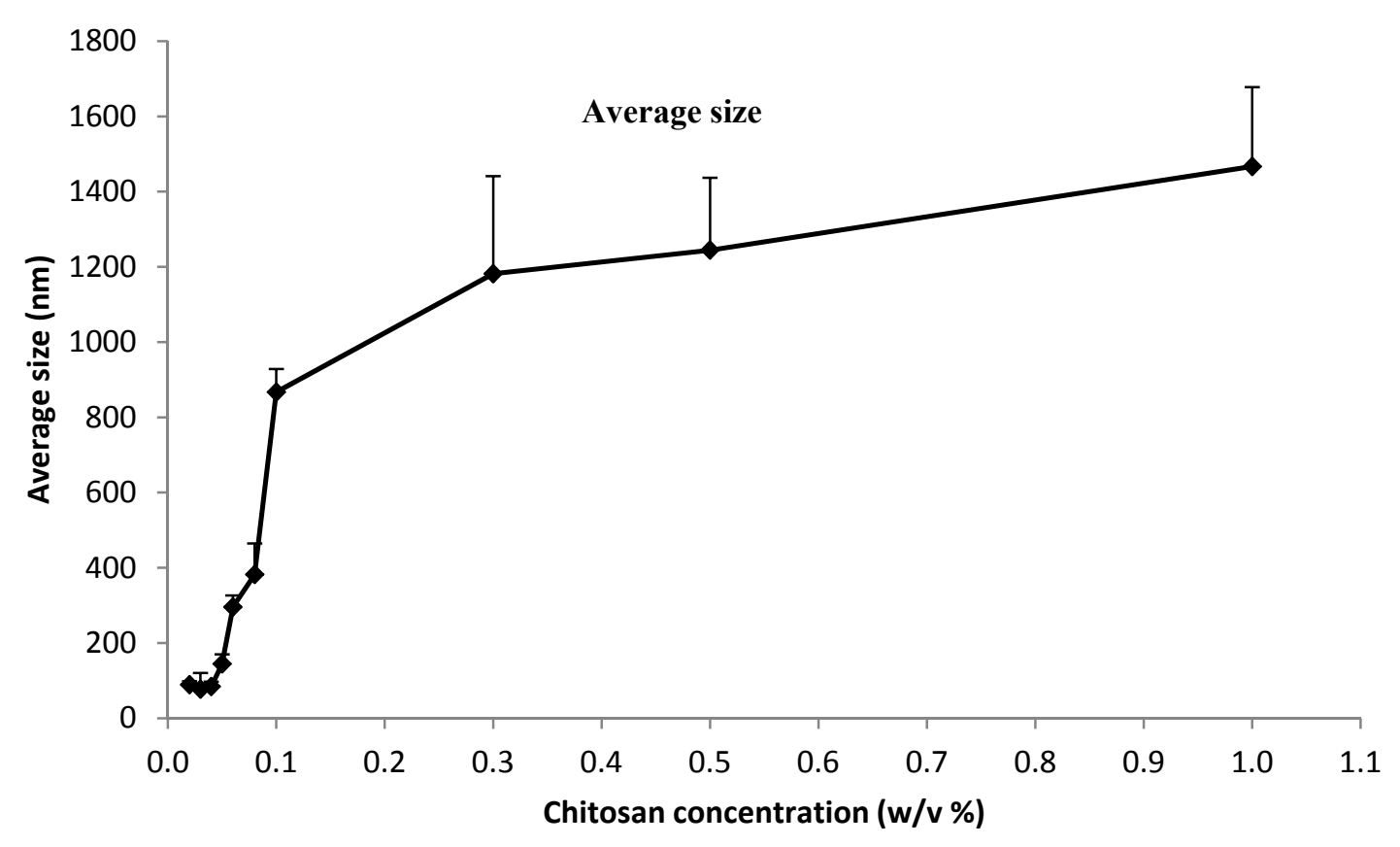

Figure 1. Mean particle sizes \pm SD ( $n=3$ ) of pUMVC3-hIL12 loaded chitosan nanoparticles (F1-F10).

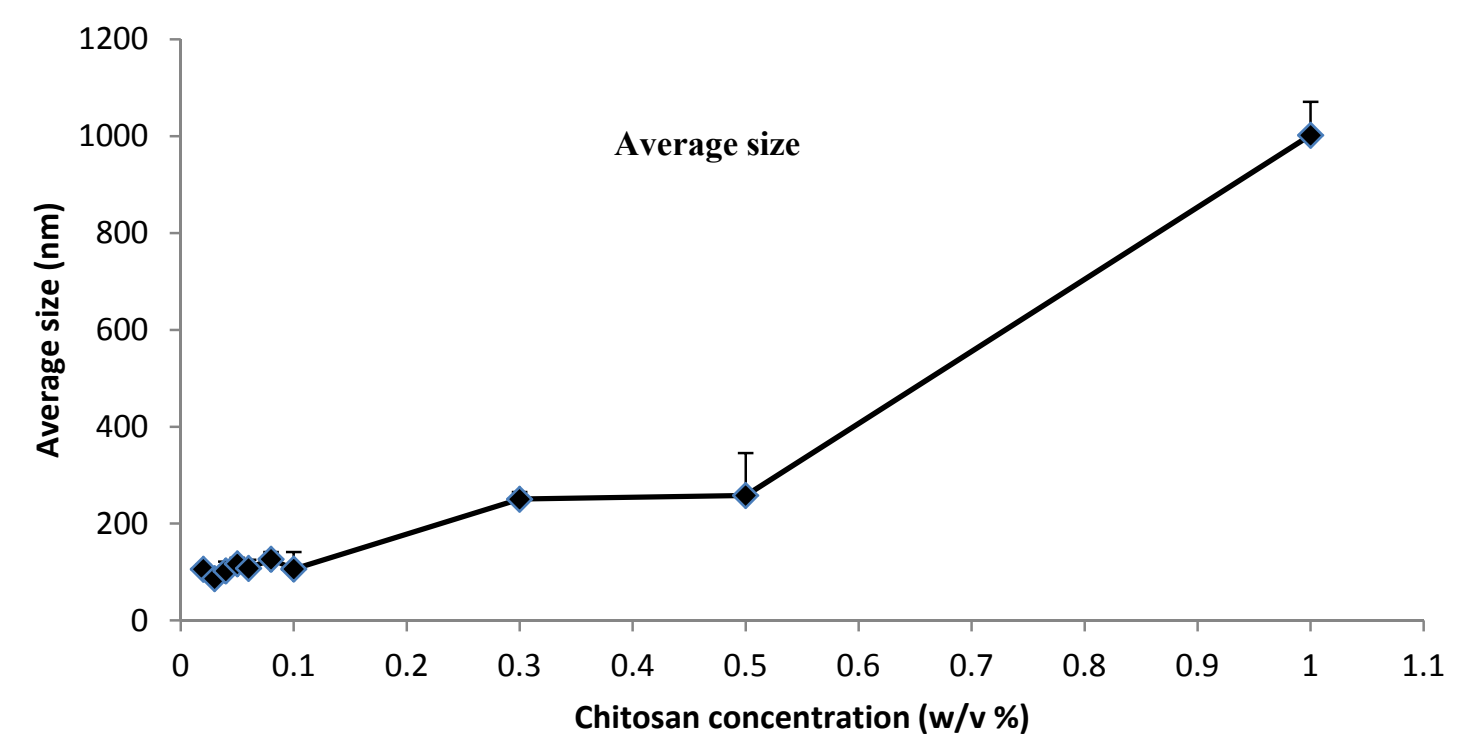

Figure 2. Mean particle sizes \pm SD ( $n=3$ ) of pUMVC3-hIL12 loaded chitosan nanoparticles (F11-F20). 


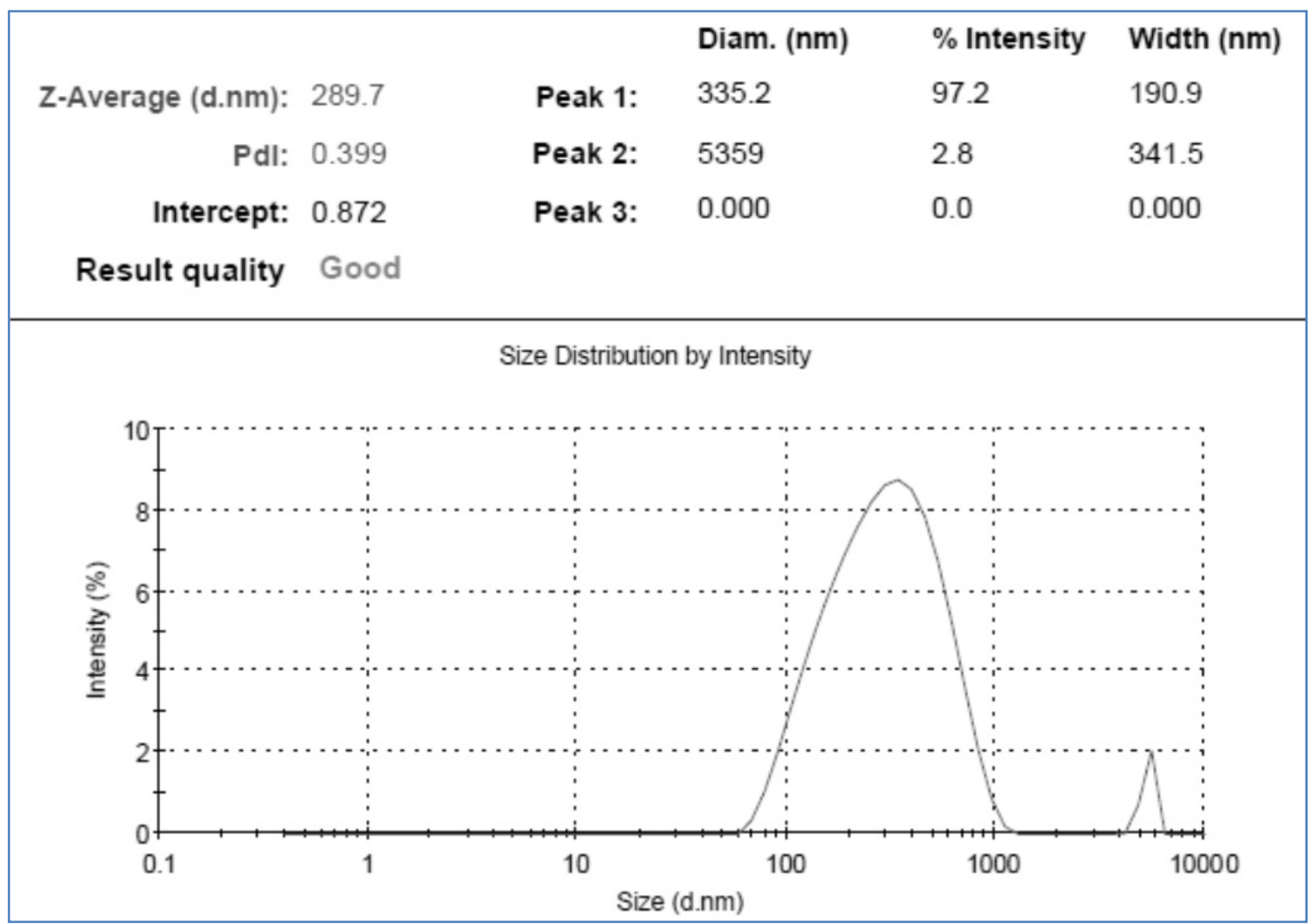

Figure 3. Particle size distribution profiles of pUMVC3-hIL12 loaded chitosan nanoparticles (F6).

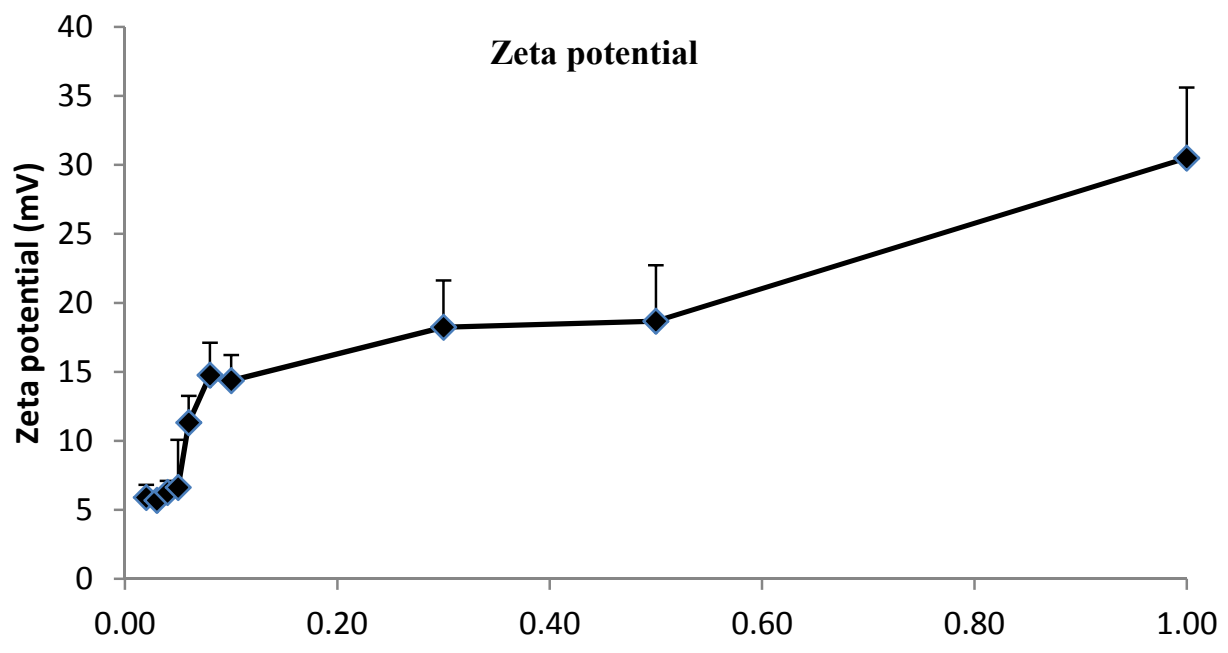

Chitosan concentration ( $w / v \%)$

Figure 4. Mean zeta potential \pm SD ( $\mathrm{n}=3$ ) of pUMVC3-hIL12 loaded chitosan nanoparticles (F1-F10). 


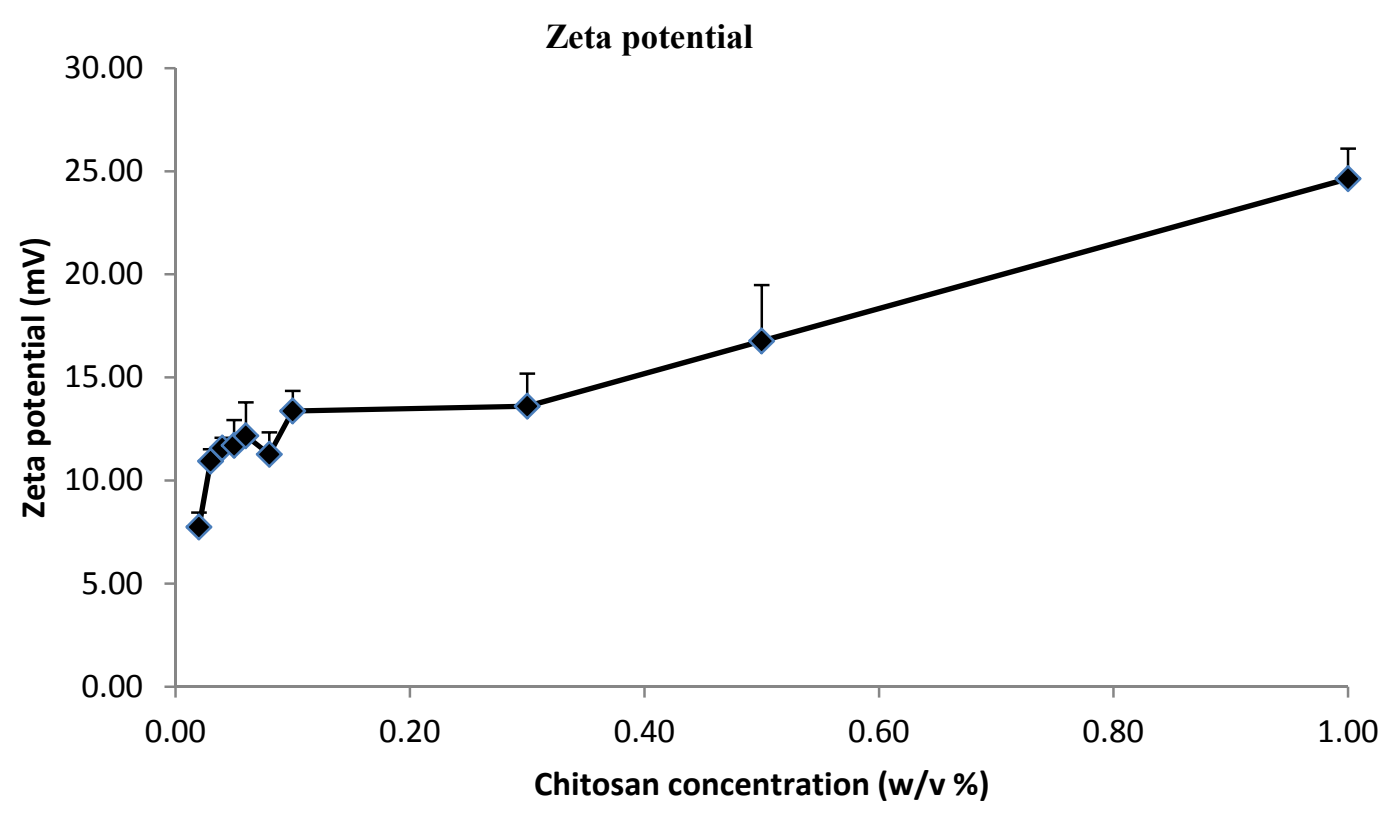

Figure 5. Mean zeta potential $\pm \mathrm{SD}(\mathrm{n}=3)$ of pUMVC3-hIL12 loaded chitosan nanoparticles (F11-F20).

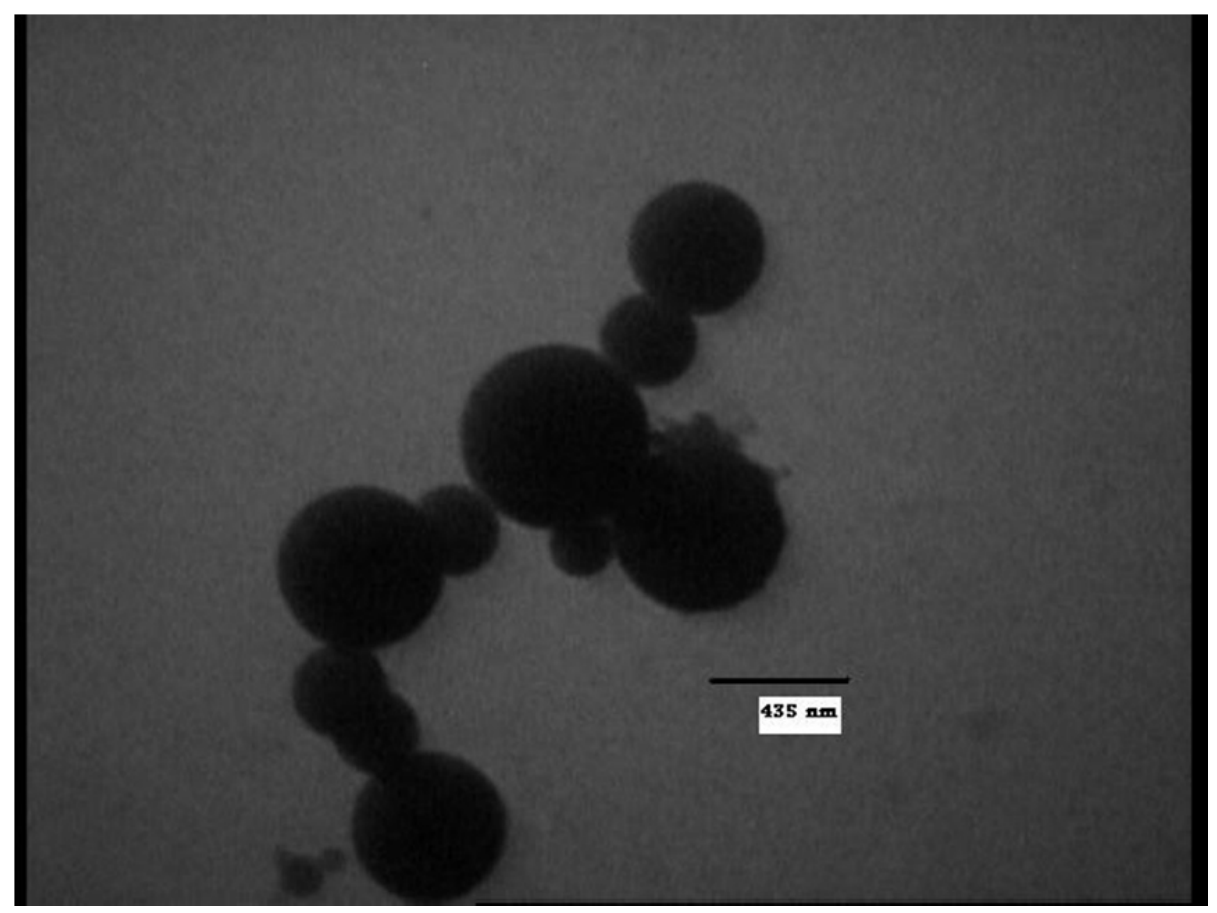

Figure 6. Transmission electron microscopy (TEM) photograph of pUMVC3-hIL12 loaded chitosan nanoparticles (F6). 


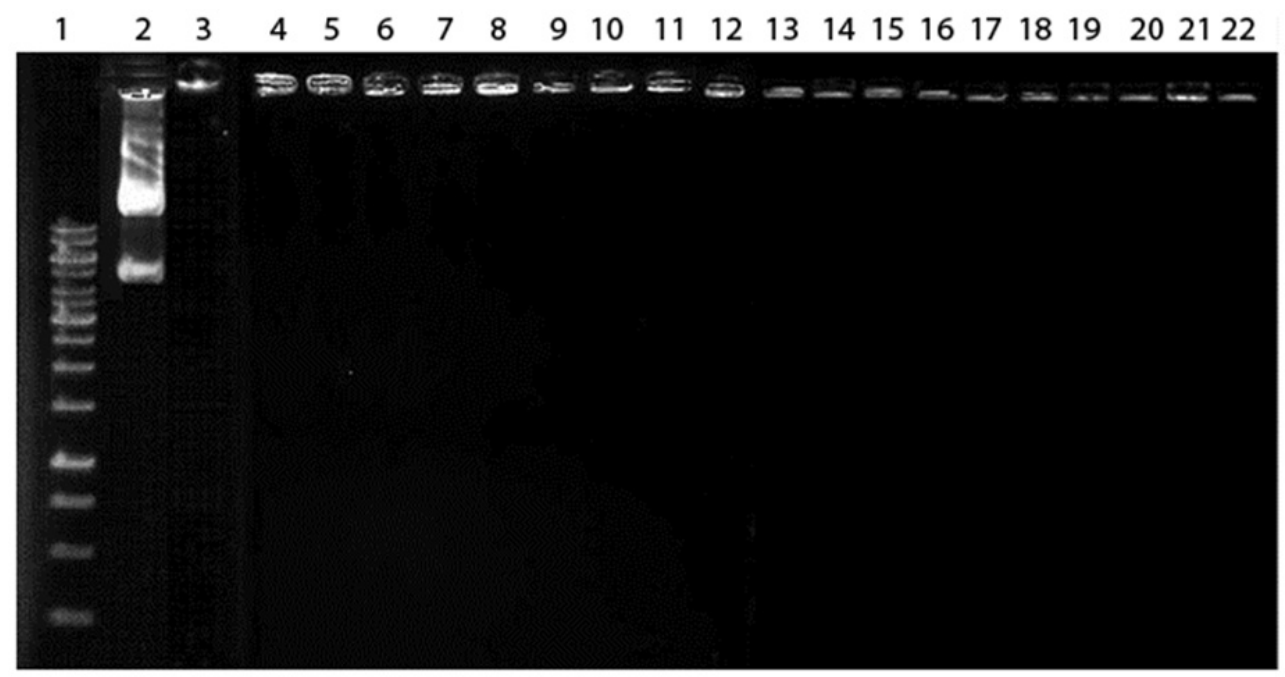

Figure 7. Electrophoretic analysis of the free and the prepared plasmid DNA nanoparticles: lane1: DNA ladder, lane2: plasmid DNA, lane3-22: chitosan-DNA nanoparticles (F1-F20 respectively).

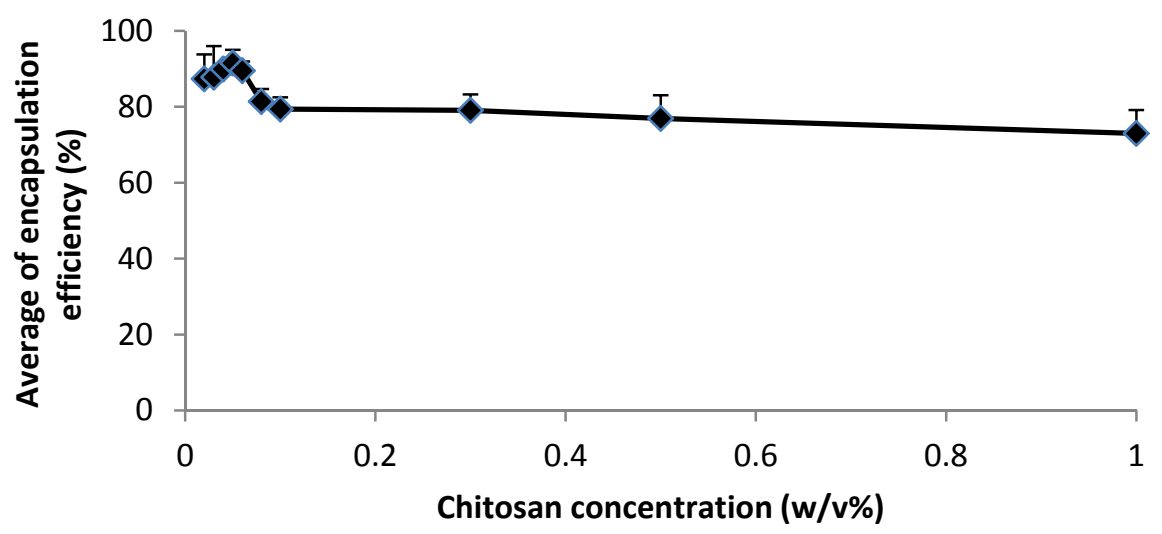

Figure 8. Mean average of encapsulation efficiency (\%) $\pm \mathrm{SD}(\mathrm{n}=3)$ of pUMVC3-hIL12 loaded chitosan nanoparticles (F1F11).

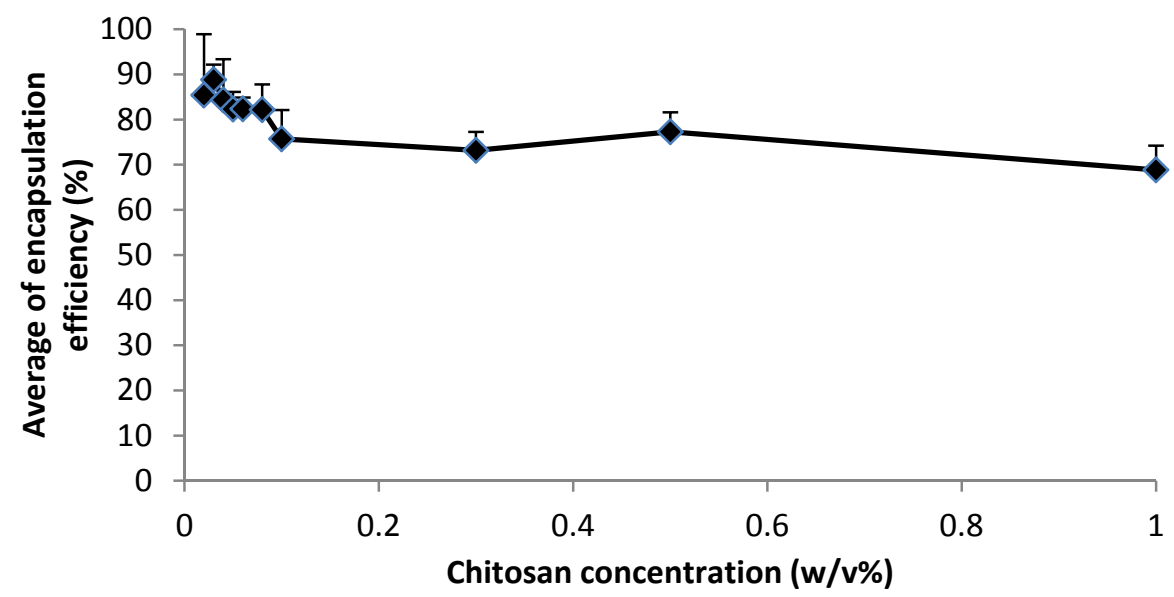

Figure 9. Mean average of encapsulation efficiency $(\%) \pm \mathrm{SD}(\mathrm{n}=3)$ of pUMVC3-hIL12 loaded chitosan nanoparticles (F12F22). 


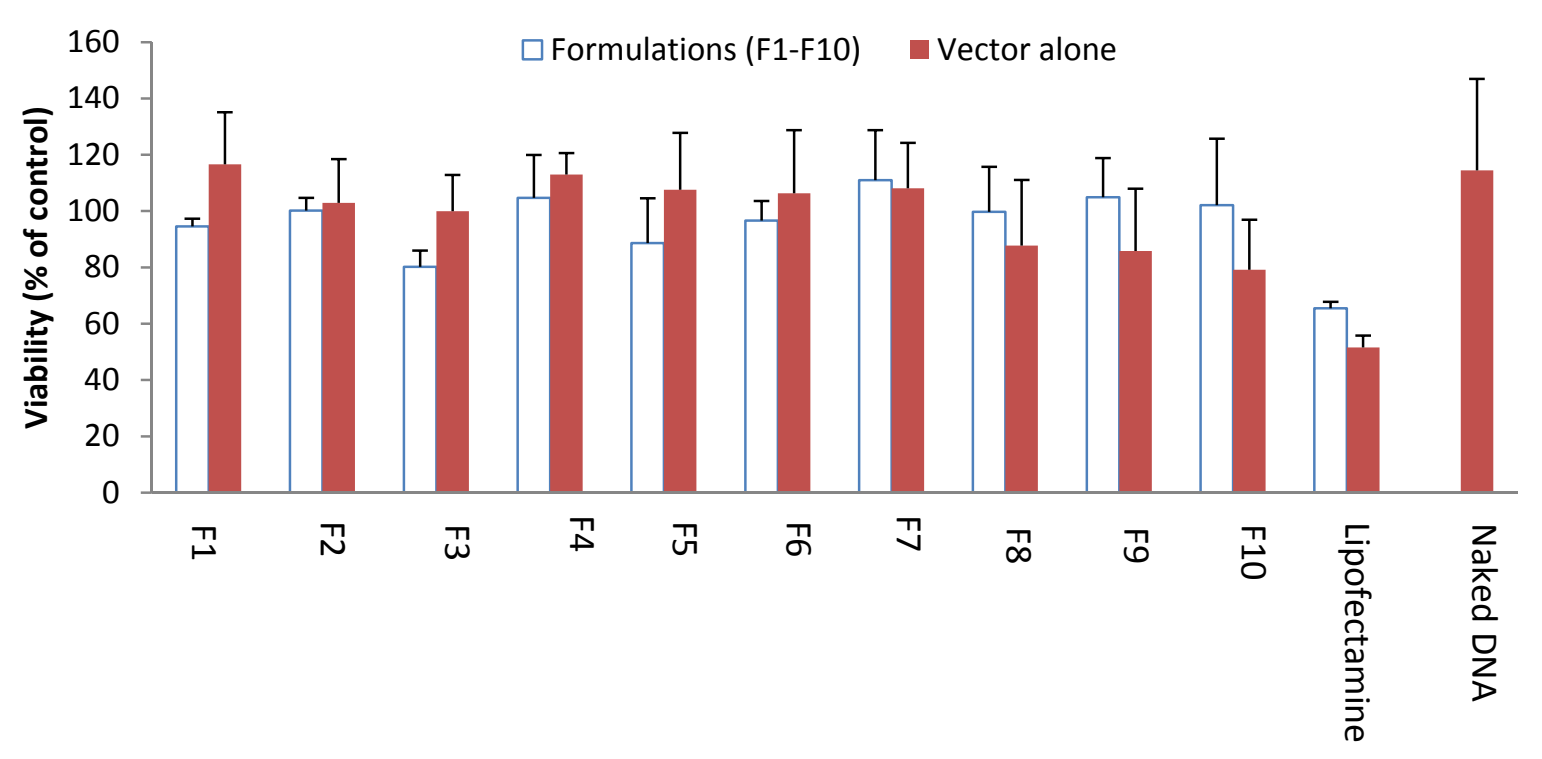

Figure 10. Mean Viability \pm SD ( $n=4)$ of CT-26 colon adenocarcinoma cells after treatment with chitosan-DNA complexes (F1-F10). Naked plasmid DNA, and Lipofectamin, were used for comparison. Relative cell viabilities were approximately $90 \%$ for almost all chitosan-DNA complexes. In contrast, Lipofectamine/phIL-12 complex-based treatment resulted in less than $70 \%$ cell viability, ( $\square=$ nanoparticles; $\mathbf{-}=$ vector alone).

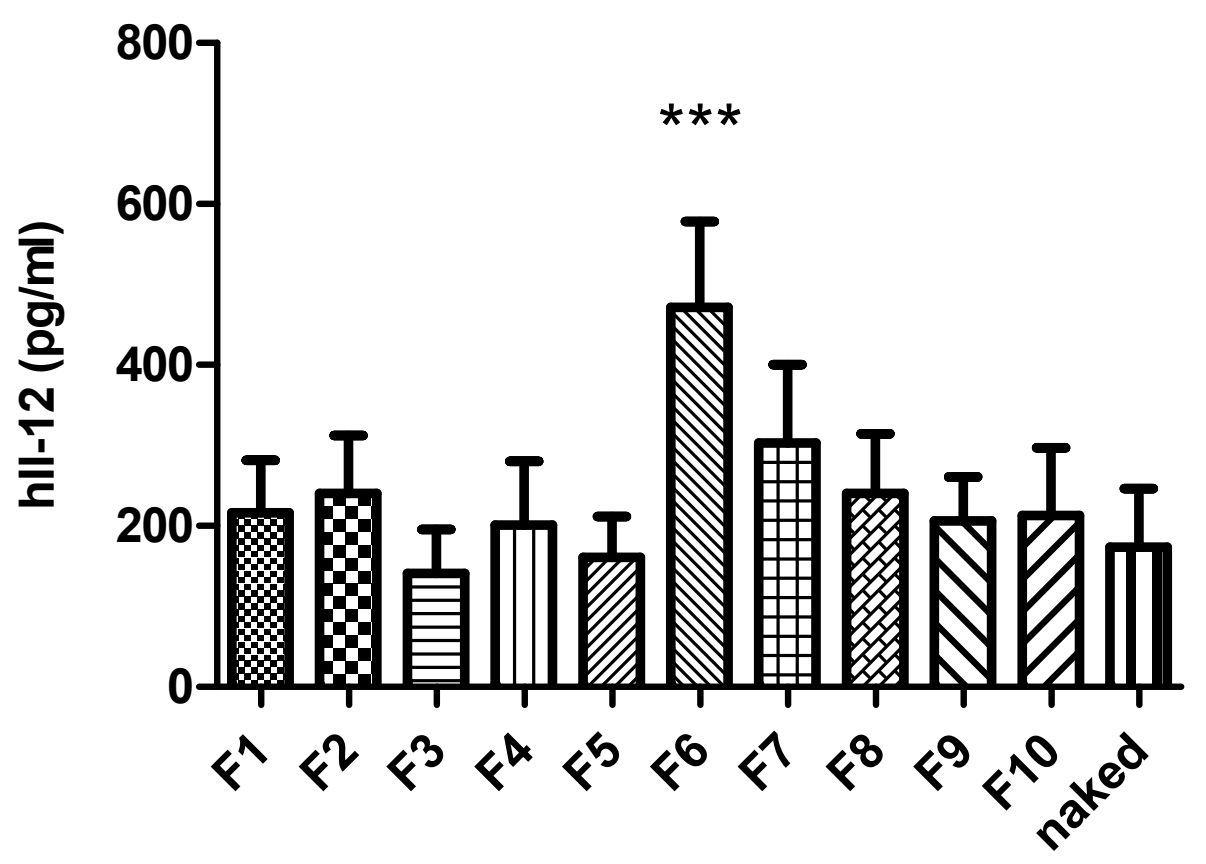

Figure 11. CT-26 colon adenocarcinoma cells were treated with chitosan-DNA complexes (F1-F10) and naked plasmid DNA for 4 hours and ELISA was performed at 48 hours post treatment. The bars and error bars represent the hIl-12 concentration $(\mathrm{n}=6)$ and the corresponding standard deviations. DNA/chitosan formulations showed maximum transfection efficiency at N/P ratios of 16 (F6). ${ }^{* * *} \mathrm{p}<0.05$, significantly different compared with the naked plasmid DNA. 

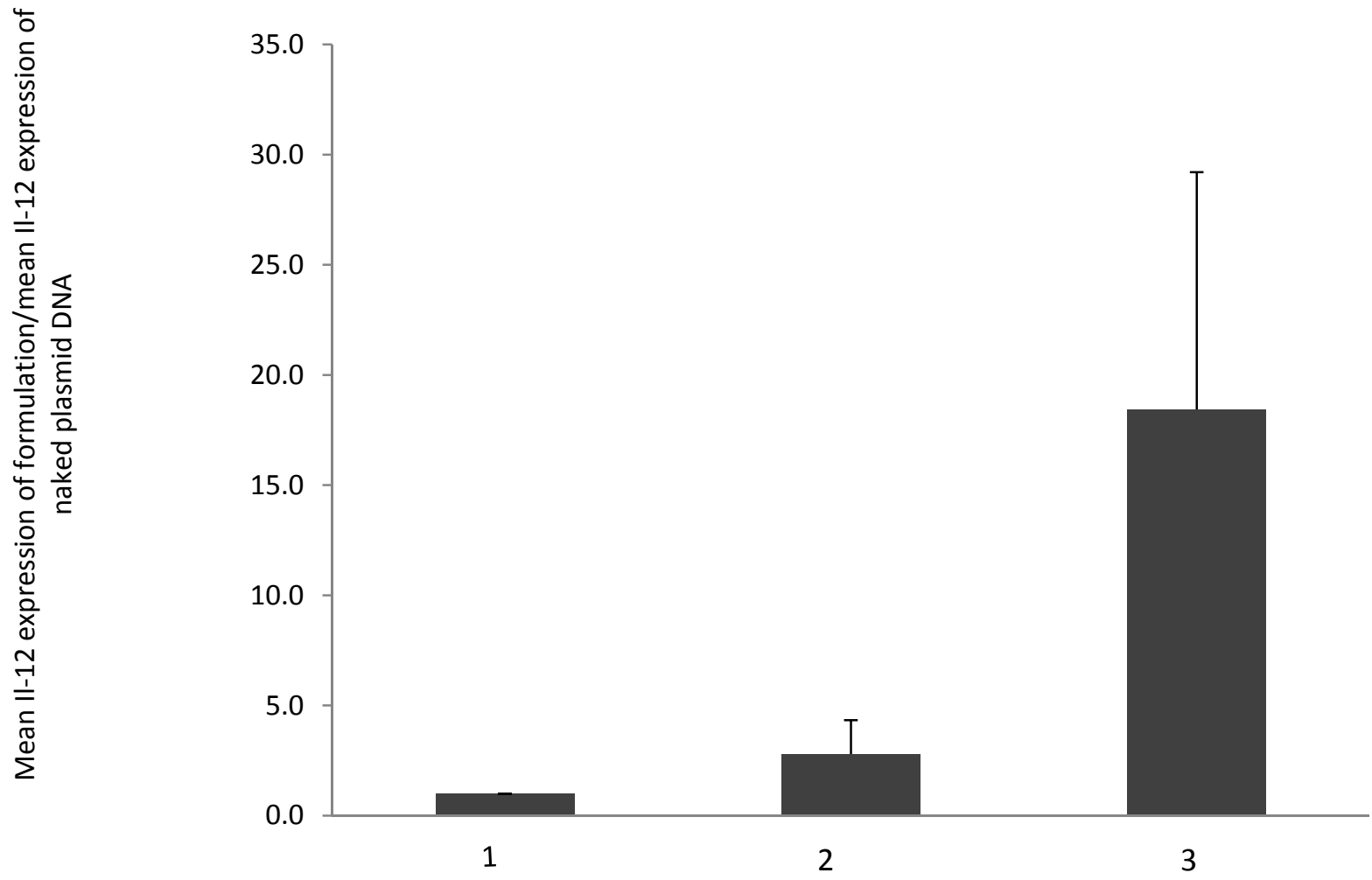

Figure 12. 1) Mean IL-12 expression of naked plasmid DNA \pm SD ( $n=6)$ which is arbitrarily considered as 1 , 2) Mean IL12 expression of F6 \pm SD $(n=6) /$ mean IL-12 expression of naked plasmid DNA \pm SD ( $n=6)$, 3) Mean IL-12 expression of Lipofectamine \pm SD $(n=6) /$ mean IL-12 expression of naked plasmid DNA \pm SD $(n=6)$. DNA/chitosan nanoparticles could improve transfection of pUMVC3-hIL12 about 2.80 orders of magnitude compared to the naked plasmid DNA. The transfection ability of F6 was less effective than that of the lipofectamine formulation in the studied gene-cell combination.

There are different methods to prepare chitosan nanoparticles which include chemical crosslinking, the emulsification solvent diffusion method, complex coacervation and ionotropic gelation; which have been reviewed by Tan et al. (24). Among those methods, complex coacervation is simple, quick, economical, and requires no toxic solvents compared to the other approaches. Thus, pUMVC3-hIL12 loaded chitosan nanoparticles were prepared via this method. Following the preparation of the nanoparticles, they were characterized in terms of size, zeta potential, morphology, encapsulation efficiency, cytotoxicity, and finally in vitro transfection ability. The size of pDNA-loaded chitosan particles was found to be dependent on the N/P ratio and increased with the increasing of $\mathrm{N} / \mathrm{P}$ ratio. According to the results, at N/P ratios above 6 , the complexes were nanosized and complete complexes were formed. Also, the shape of the polyplexes according to TEM was found to be spherical (Figure 6).

Moreover, chitosan/DNA nanopartcles prepared using $200 \mu \mathrm{g} / \mathrm{ml} \mathrm{pDNA}$ at higher N/P ratios (F11F18) exhibited higher polydispersity index which indicates that while overall particle sizes of these nanoparticles were reasonable, polyplexes prepared using $200 \mu \mathrm{g} / \mathrm{ml} \mathrm{pDNA}$ at higher N/P ratios showed more heterogeneous distribution of the particle size. This indicates that the amount of 
polymer and DNA, each of which as well as the $\mathrm{N} / \mathrm{P}$ ratio had noticeable influence on the uniformity of the particle size (Table 1).

In general, zeta potential is one of the important particle characteristics. Firstly, in view of the fact that more pronounced zeta potential values lead to stabilization of the particle suspension due to the electrostatic repulsion between particles with the same electric charges which prevents aggregation (38). Secondly, the positively charged particles can facilitate adherence to negatively charged cellular membranes which will induce and increase intracellular uptake. The positive zeta potential increased by increasing the chitosan concentrations in constant DNA levels (Figure 4 and 5) indicating that the N/P ratio influence the zeta potential.

Based on the results, the nanoparticles demonstrated good mean DNA association efficiencies of $68.8 \%$ to $91.5 \%$. This fact is in agreement with the previous results obtained for other chitosan nanoparticles, and is due to the high affinity of chitosan to DNA. As reported previously (49), the bound between chitosan and anionic DNA was very stable owing to the strong ionic interaction between the plasmid and polymer. Also hydrophobic interactions or hydrogen bonds between the organic bases of the nucleotide and the sugar structure of polymer are very important in the stability. These results support the hypothesis of multiple interactions between chitosan and pDNA.

In addition, all prepared complexes at concentrations higher than those used for transfection evaluations, showed no acute cell toxicity with average cell viability of almost over $90 \%$ in murine CT-26 colon carcinoma cells (Figure 10). Having low toxicity will make it possible to increase the dose of the DNA/chitosan complexes or to use repeated administrations. More to the point, the transfection efficiency of polymeric carriers is strongly affected by the cytotoxicity of the used cationic polymers, owing to the electrostatic interactions with the negatively charged cellular membranes $(38,50)$. Thus, the differences in transfection efficiency between the formulations cannot be due to the different toxicities, as in all formulations, cell viabilities were almost similar.

The N/P ratios which affect the size and the overall charge density of the complexes can also influences polyplexes' transfection efficiency. As mentioned in results section (Figure 11), the transfection abilities of chitosan/DNA formulations at $\mathrm{N} / \mathrm{P}$ ratios of $4-12$ were not considerably different from the naked plasmid DNA. However, there are remarkable increase in the transfection efficiencies of DNA/chitosan formulations at N/P ratios between 16 and 60 . The relationship between transfection efficiencies and $\mathrm{N} / \mathrm{P}$ ratios in chitosan-DNA complexes has been demonstrated in an earlier research done by Lavertu et al. (51).

DNA/chitosan formulations showed maximum transfection efficiency at N/P ratio of 16 with mean particle size of $381.83 \mathrm{~nm}$ (mean polydispersity index=0.406). Therefore, DNA/chitosan nanoparticles could improve transfection of pUMVC3-hIL12 about 2.80 orders of magnitude in murine CT-26 colon carcinoma cells compared to the naked pUMVC3-hIL12. Transfection with all formulations prepared using $200 \mu \mathrm{g} / \mathrm{ml}$ pDNA (F11-F20) were not considerably different from naked plasmid DNA (data not shown) which indicated that the N/P ratio and the amount of each of polymer and DNA had great influence on the gene transfection of chitosan/DNA complexes.

At low N/P ratios, the transfection efficiencies of all chitosan/DNA complexes were not considerably different from that of the naked DNA. This might be due to low amount of positively charged amines of chitosan in the chitosan-DNA complexes which could not sufficiently help to increase the transfection ability. The chitosan/DNA complexes achieved sufficient transfection efficiencies at higher N/P ratios (between 16 and 60). Moreover, it has been reported that the positively charged chitosan is able to decrease the trans-epithelial electrical resistance (TEER) of cell monolayers besides to increase paracellular permeability. Positive charges of chitosan is capable of interaction with the tight junction proteins occludin and $\mathrm{ZO}-1$, redistribution of $\mathrm{F}$ actin, and slight destabilization of the plasma membrane (52). It can be discussed that an optimum N/P ratio could yield most favorable positively charged complexes to successfully transfect cells. Also, the transfection efficiency of the chitosan-DNA complex was correlated positively with the incubation time (data not shown).

Based on the above findings, the chitosan/DNA complexes prepared at charge ratio 16-60 will be 
chosen for further in vivo study in combination with other systemic chemotherapy in future.

\section{CONCLUSION}

On the whole, researches aimed to develop gene carrier systems for the expression of human IL-12, are very restricted and insufficient. In this investigation, we intended to prepare the plasmid DNA loaded chitosan nanoparticles for expression of Il-12, and to investigate the physicochemical characteristics, cytotoxicity and transfection efficiency of the prepared complexes in murine CT-26 colon carcinoma cells. Basically to perform any gene therapy with either viral or non-viral vectors, it is critical to develop sufficient gene delivery systems and to perform their in vitro evaluations. Chitosan nanoparticles (F6) at $(\mathrm{N} / \mathrm{P}=$ 16) with mean particle size of $381.83 \mathrm{~nm}$ showed maximum level of phIL-12 expression in murine CT-26 colon carcinoma cells. This research can be considered as a basis for complementary studies of chitosan-DNA polyplexes both in vitro and in vivo which has been recently shown to be potential gene carrier.

\section{REFERENCES}

1. Curiel, D T.; Douglas JT., Cancer Gene Therapy. Humana Press Inc, Totowa, NJ, 2005.

2. Cortesina G, De Stefani A, Sacchi M, Rosso S, Galeazzi E. Immunomodulation therapy for squamous cell carcinoma of the head and neck. Head Neck, 1993; 15:266-70.

3. Kresina TF. An Introduction to Molecular Medicine and Gene Therapy. A JOHN WILEY \& SONS, INC, New York, 2001.

4. Brunda MJ, Luistro L, Warrier RR, Wright RB, Hubbard BR, Murphy M, et al. Antitumor and antimetastatic activity of interleukin 12 against murine tumors. J Exp Med, 1993; 178:1223-30.

5. Ma X, Trinchieri G. Regulation of interleukin-12 production in antigen-presenting cells. $\mathrm{Adv}$ Immunol, 2001; 79:55-92.

6. Skeen MJ, Miller MA, Shinnick TM, Ziegler HK. Regulation of murine macrophage IL-12 production. Activation of macrophages in vivo, restimulation in vitro, and modulation by other cytokines. J Immunol, 1996; 15:1196-206.

7. Fallarino F, Uyttenhove C, Boon T, Gajewski TF. Endogenous IL-12 is necessary for rejection of P815 tumor variants in vivo. J Immunol, 1996; 156:1095100.
8. Rodolfo M, Colombo MP. Interleukin-12 as an adjuvant for cancer immunotherapy. Methods, 1999; 1:114-20.

9. Noguchi Y, Richards EC, Chen YT, Old LJ. Influence of interleukin 12 on p53 peptide vaccination against established Meth A sarcoma. Proc Natl Acad Sci U S A, 1995; 92:2219-23.

10. Colombo MP, Trinchieri G. Interleukin-12 in antitumor immunity and immunotherapy. Cytokine Growth Factor Rev, 2002; 13:155-68.

11. Albini A, Brigati C, Ventura A, Lorusso G, Pinter $\mathrm{M}$, Morini $\mathrm{M}$, et al. Angiostatin anti-angiogenesis requires IL-12: the innate immune system as a key target. J Transl Med, 2009; 7:5.

12. Siddiqui F, Ehrhart EJ, Charles B, Chubb L, Li CY, Zhang $X$, et al. Anti-angiogenic effects of interleukin-12 delivered by a novel hyperthermia induced gene construct. Int J Hyperthermia, 2006; 22:587-606.

13. Voest EE, Kenyon BM, O'Reilly MS, Truitt G, D'Amato RJ, Folkman J. Inhibition of angiogenesis in vivo by interleukin 12. J Natl Cancer Inst, 1995; 8:581-6.

14. Car BD, Eng VM, Lipman JM, Anderson TD. The toxicology of interleukin-12: a review. Toxicol Pathol, 1999; 27:58-63.

15. Yockman JW, Maheshwari A, Han SO, Kim SW. Tumor regression by repeated intratumoral delivery of water soluble lipopolymers/p2CMVmIL-12 complexes. J Control Release, 2003; 87:177-86.

16. Tan J, Newton CA, Djeu JY, Gutsch DE, Chang AE, Yang NS, et al. Injection of complementary DNA encoding interleukin-12 inhibits tumor establishment at a distant site in a murine renal carcinoma model. Cancer Res, 1996; 56:3399-403.

17. Davis ME. Non-viral gene delivery systems. Curr Opin Biotechnol, 2002; 13:128-31.

18. Schmidt-Wolf GD, Schmidt-Wolf IG. Non-viral and hybrid vectors in human gene therapy: an update. Trends Mol Med, 2003; 9:67-72.

19. Alonso MJ. Nanomedicines for overcoming biological barriers. Biomed Pharmacother, 2004; 58:168-72.

20. Basarkar A, Singh J. Nanoparticulate systems for polynucleotide delivery. Int J Nanomedicine, 2007; 2:353-60.

21. Huang, L.; Hung MCH.; Wagner, E., Non-viral Vectors for Gene Therapy. Elsevier Inc, California, USA, 2005.

22. Guang Liu W, De Yao K. Chitosan and its derivatives--a promising non-viral vector for gene transfection. J Control Release, 2002; 83:1-11.

23. Dass CR, Choong PF. Chitosan-mediated orally delivered nucleic acids: a gutful of gene therapy. J Drug Target, 2008;16:257-61. 
24. Tan ML, Choong PF, Dass CR. Cancer, chitosan nanoparticles and catalytic nucleic acids. J Pharm Pharmacol, 2009; 61:3-12.

25. Baldrick P. The safety of chitosan as a pharmaceutical excipient. Regul Toxicol Pharmacol. Apr;56(3):290-9.

26. Lai WF, Lin MC. Nucleic acid delivery with chitosan and its derivatives. J Control Release, 2009; 134:158-68.

27. Borchard G. Chitosans for gene delivery. Adv Drug Deliv Rev, 2001; 52:145-50.

28. Patil SD, Rhodes DG, Burgess DJ. DNA-based therapeutics and DNA delivery systems: a comprehensive review. AAPS J, 2005; 7:E61-77.

29. Zitvogel L, Tahara H, Cai Q, Storkus WJ, Muller G, Wolf SF, et al. Construction and characterization of retroviral vectors expressing biologically active human interleukin-12. Hum Gene Ther, 1994; 5:1493-506.

30. Meko JB, Yim JH, Tsung K, Norton JA. High cytokine production and effective antitumor activity of a recombinant vaccinia virus encoding murine interleukin 12. Cancer Res, 1995; 55:4765-70.

31. Chen L, Chen D, Block E, O'Donnell M, Kufe DW, Clinton SK. Eradication of murine bladder carcinoma by intratumor injection of a bicistronic adenoviral vector carrying cDNAs for the IL-12 heterodimer and its inhibition by the IL-12 p40 subunit homodimer. J Immunol, 1997; 159:351-9.

32. Faneca H, Cabrita AS, Simoes S, Pedroso de Lima MC. Evaluation of the antitumoral effect mediated by IL-12 and HSV-tk genes when delivered by a novel lipid-based system. Biochim Biophys Acta, 2007; 1768:1093-102.

33. Speroni L, Gasparri J, de los ABV, Chiaramoni NS, Smagur A, Szala S, et al. Antitumoral effect of IL12 gene transfected via liposomes into B16F0 cells. Acta Biochim Pol, 2009; 56:249-53.

34. Daud AI, DeConti RC, Andrews S, Urbas P, Riker AI, Sondak VK, et al. Phase I trial of interleukin-12 plasmid electroporation in patients with metastatic melanoma. J Clin Oncol, 2008; 26:5896-903.

35. Maheshwari A, Mahato RI, McGregor J, Han S, Samlowski WE, Park JS, et al. Soluble biodegradable polymer-based cytokine gene delivery for cancer treatment. Mol Ther, 2000; 2:121-30.

36. Fewell JG, Matar M, Slobodkin G, Han SO, Rice J, Hovanes B, et al. Synthesis and application of a nonviral gene delivery system for immunogene therapy of cancer. J Control Release, 2005; 109:288-98.

37. Wang Y, Gao S, Ye WH, Yoon HS, Yang YY. Codelivery of drugs and DNA from cationic core-shell nanoparticles self-assembled from a biodegradable copolymer. Nat Mater, 2006; 5:791-6.

38. Diez S, Migueliz I, Tros de Ilarduya C. Targeted cationic poly(D,L-lactic-co-glycolic acid) nanoparticles for gene delivery to cultured cells. Cell Mol Biol Lett, 2009; 14:347-62.

39. Chew JL, Wolfowicz CB, Mao HQ, Leong KW, Chua KY. Chitosan nanoparticles containing plasmid DNA encoding house dust mite allergen, Der $\mathrm{p} 1$ for oral vaccination in mice. Vaccine, 2003; 21:2720-9.

40. Gao Y, Zhang Z, Chen L, Gu W, Li Y. Chitosan Nbetainates/DNA self-assembly nanoparticles for gene delivery: in vitro uptake and transfection efficiency. Int J Pharm, 2009; 371:156-62.

41. Corsi K, Chellat F, Yahia L, Fernandes JC. Mesenchymal stem cells, MG63 and HEK293 transfection using chitosan-DNA nanoparticles. Biomaterials, 2003; 24:1255-64.

42. Mao HQ, Roy K, Troung-Le VL, Janes KA, Lin KY, Wang Y, et al. Chitosan-DNA nanoparticles as gene carriers: synthesis, characterization and transfection efficiency. J Control Release, 2001; 70:399-421.

43. Sato $T$, Ishii $T$, Okahata $Y$. In vitro gene delivery mediated by chitosan. effect of $\mathrm{pH}$, serum, and molecular mass of chitosan on the transfection efficiency. Biomaterials, 2001; 22:2075-80.

44. Lee $\mathrm{CH}$, Ni YH, Chen CC, Chou C, Chang FH. Synergistic effect of polyethylenimine and cationic liposomes in nucleic acid delivery to human cancer cells. Biochim Biophys Acta, 2003; 1611:55-62.

45. Ishii T, Okahata Y, Sato T. Mechanism of cell transfection with plasmid/chitosan complexes. Biochim Biophys Acta, 2001; 1514:51-64.

46. Ozgel G, Akbuga J. In vitro characterization and transfection of IL-2 gene complexes. Int J Pharm. 2006; 315:44-51.

47. Han S, Mahato RI, Sung YK, Kim SW. Development of biomaterials for gene therapy. Mol Ther, 2000; 2:302-17.

48. Anwer K, Rhee BG, Mendiratta SK. Recent progress in polymeric gene delivery systems. Crit Rev Ther Drug Carrier Syst, 2003; 20:249-93.

49. Li XW, Lee DK, Chan AS, Alpar HO. Sustained expression in mammalian cells with DNA complexed with chitosan nanoparticles. Biochim Biophys Acta, 2003; 1630:7-18.

50. Fischer D, Li Y, Ahlemeyer B, Krieglstein J, Kissel $\mathrm{T}$. In vitro cytotoxicity testing of polycations: influence of polymer structure on cell viability and hemolysis. Biomaterials, 2003; 24:1121-31.

51. Lavertu M, Methot S, Tran-Khanh N, Buschmann MD. High efficiency gene transfer using chitosan/DNA nanoparticles with specific combinations of molecular weight and degree of deacetylation. Biomaterials, 2006; 27:4815-24.

52. Bowman K, Leong KW. Chitosan nanoparticles for oral drug and gene delivery. Int $\mathrm{J}$ Nanomedicine, 2006; 1:117-28. 